\title{
Exercise is medicine for depression: even when the "pill" is small
}

\author{
This article was published in the following Dove Press journal: \\ Neuropsychiatric Disease and Treatment \\ 25 October 2016 \\ Number of times this article has been viewed
}

\author{
Mats Hallgren' \\ Davy Vancampfort ${ }^{2,3}$ \\ Brendon Stubbs ${ }^{4,5}$ \\ 'Department of Public Health \\ Sciences, Karolinska Institutet, \\ Stockholm, Sweden; ${ }^{2}$ Department of \\ Rehabilitation Sciences, ${ }^{3}$ University \\ Psychiatric Centre - KU Leuven, \\ KU Leuven - University of Leuven, \\ Leuven, Belgium; ${ }^{4}$ Department \\ of Physiotherapy, South London \\ and Maudsley NHS Foundation \\ Trust, ${ }^{5}$ Department of Health \\ Service and Population Research, \\ Institute of Psychiatry, Psychology \\ and Neuroscience, King's College \\ London, London, UK
}

\section{Dear editor}

In a recent perspectives article, Gerber et al argue persuasively that more systematic efforts are needed to utilize the considerable treatment potential of exercise in psychiatric care. ${ }^{1}$ Specifically, the authors highlight the inherent difficulties that clinicians and researchers face when encouraging patients to initiate and maintain a regular physical activity program. These obstacles relate to dysfunctional cognitiveemotional processes which, the authors argue, can interfere with patients' capacity to self-regulate health-related behaviors such as exercise. They further suggest that behavioral skill training should be used to support patients with major depressive disorders (MDDs), and that the assessment of physical activity and cardiorespiratory fitness should be routine in psychiatric practice. Finally, the authors comment on the optimal exercise dose, and draw attention to the paucity of studies exploring the long-term effects of exercise on depression. We commend the authors for their timely recommendations and concur with their main suggestions. In this brief letter, we wish to complement Gerber's excellent article with three key points.

First, we wish to reemphasize the importance of interventions that aim to improve the physical health of those with depression. While suicide accounts for some of the premature deaths among people with MDDs, it is now established that high levels of cardiovascular and metabolic disease in this population ${ }^{2,3}$ are leading contributors to the premature mortality gap of 10-15 years in people with depression compared to the general population. ${ }^{4}$ It has also been shown that individuals who maintain their cardiorespiratory fitness across the lifespan have a reduced risk of experiencing a depressive episode, ${ }^{5}$ in addition to other detrimental health outcomes, such as cardiovascular disease and diabetes. Reducing these cardio-metabolic health problems is unlikely to be achieved as efficiently through antidepressant use or other psychological interventions alone.

Second, we agree that supported exercise interventions involving trained health professionals, such as exercise physiologists, psychologists and nurses, are necessary to optimize treatment outcomes. Recent meta-analyses have demonstrated that cardiorespiratory fitness gains from exercise are higher, and dropout levels lower, when recognized exercise professionals are used. ${ }^{6,7}$ Indeed a review of the program variables in exercise for depression studies concluded that individually tailoring exercise to suit the client's preference, access to facilities and ensuring supervision are ways to enhance treatment outcomes. ${ }^{8}$ In practical terms, this can be achieved through weekly face-to-face contact with a qualified health professional where goal setting is discussed and exercise benefits and barriers reviewed, or through "remote" contact
Correspondence: Mats Hallgren Department of Public Health Sciences, Karolinska Institutet, Solna, Stockholm I7I 77, Sweden Email mats.hallgren@ki.se
Neuropsychiatric Disease and Treatment 2016:12 2715-2721

2715 
using email and text messaging to encourage adherence to exercise regimes. While plausible, Gerber's suggestion that "major therapeutic efforts are required to decrease the unfavorable cognitive-emotional processes experienced by patients with MDDs" (p 1979) has yet to be empirically tested in the context of exercise training. Further research is needed to determine what constitutes optimal supervision of this patient group.

Finally, we wish to comment on the "dose" of exercise needed to obtain clinically meaningful treatment effects. Gerber et al cite a previous efficacy study performed in a laboratory setting indicating that exercise needs to be performed at "public health doses" to achieve a treatment effect. ${ }^{9}$ While this groundbreaking and well-executed study remains relevant today, findings from effectiveness trials can also inform this discussion. For example, in a recent community-based trial, Hallgren et al randomized 946 outpatients with mild-to-moderate depression to one of three 12-week interventions: supervised physical exercise, internet-based cognitive behavioral therapy (CBT) and usual care by a physician, consisting of CBT-focused therapy and antidepressant treatment. ${ }^{10}$ Participants in the exercise condition were further randomized to one of three exercise intensities: light exercise consisting of yoga and stretching (without a mindfulness component), moderate aerobic exercise or vigorous aerobic exercise. All sessions were calibrated and conducted in established fitness facilities with qualified instructors. Although participants were encouraged to complete three exercise sessions per week (36 in total), most only attended about 1 exercise class per week. At posttreatment, patients randomized to the exercise intervention reported significantly lower depression severity compared to usual care. Of importance, the positive effects of exercise on depression severity were maintained 12 months after the baseline assessment, despite suboptimal adherence. ${ }^{11}$ Moreover, the effects of exercise intensity were equivalent across groups, suggesting that all three intensities were equally effective in the treatment of mild-to-moderate depression. $^{12}$
In summary, we concur with and thank Gerber et al for their important recommendations. We also wish to highlight promising new results from community-based trials with longterm follow-up assessments indicating that exercise is indeed medicine for depression, even when the "pill" is small.

\section{Disclosure}

The authors report no conflicts of interest in this communication.

\section{References}

1. Gerber M, Holsboer-Trachsler E, Pühse U, Brand S. Exercise is medicine for patients with major depressive disorders: but only if the "pill” is taken! Neuropsychiatr Dis Treat. 2016;12:1977-1981.

2. Vancampfort D, Stubbs B, Mitchell AJ, et al. Risk of metabolic syndrome and its components in people with schizophrenia and related psychotic disorders, bipolar disorder and major depressive disorder: a systematic review and meta-analysis. World Psychiatry. 2015;14(3): 339-347.

3. Vancampfort D, Correll CU, Galling B, et al. Diabetes mellitus in people with schizophrenia, bipolar disorder and major depressive disorder: a systematic review and large scale meta-analysis. World Psychiatry. 2016;15(2):166-174.

4. Walker ER, McGee RE, Druss BG. Mortality in mental disorders and global disease burden implications: a systematic review and metaanalysis. JAMA Psychiatry. 2015;72(4):334-341.

5. Dishman RK, Sui X, Church TS, Hand GA, Trivedi MH, Blair SN. Decline in cardiorespiratory fitness and odds of incident depression. Am J Prev Med. 2012;43(4):361-368.

6. Vancampfort D, Rosenbaum S, Schuch F, et al. Cardiorespiratory fitness in severe mental illness: a systematic review and meta-analysis. Sports Med. Epub 2016 Jun 14.

7. Stubbs B, Vancampfort D, Rosenbaum S, et al. Dropout from exercise randomized controlled trials among people with depression: a metaanalysis and meta regression. $J$ Affect Disorders. 2016;190:457-466.

8. Stanton R, Reaburn P. Exercise and the treatment of depression: a review of the exercise program variables. J Sci Med Sport. 2014;17(2):177-182.

9. Dunn AL, Trivedi MH, Kampert JB, Clark CG, Chambliss HO. Exercise treatment for depression: efficacy and dose response. Am J Prev Med. 2005;28(1):1-8.

10. Hallgren M, Kraepelien M, Öjehagen A, et al. Physical exercise and internet-based cognitive behavioural therapy in the treatment of depression: randomised controlled trial. Br J Psychiatry. 2015;207(3):227-234.

11. Hallgren M, Helgadóttir B, Herring MP, et al. Exercise and internetbased cognitive behavioural therapy for depression: multicentre randomised controlled trial with 12-month follow-up. Br J Psychiatry. Epub 2016 Sep 8.

12. Helgadóttir B, Hallgren M, Ekblom Ö, Forsell Y. Training fast or slow? Exercise for depression: a randomized controlled trial. Prev Med.2016; 91:123-131. 


\section{Authors' reply}

Markus Gerber'

Edith Holsboer-Trachsler ${ }^{2}$

Uwe Pühse ${ }^{3}$

Serge Brand ${ }^{1,2}$

'Department of Sport, Exercise and Health, Division of Sport and Psychosocial Health, University of Basel, ${ }^{2}$ Center for Affective, Stress and Sleep Disorders, Psychiatric Clinics of the University of Basel, ${ }^{3}$ Department of Sport, Exercise and Health, Division of Sport and Health Pedagogy, University of Basel, Basel, Switzerland

Correspondence: Markus Gerber

Department of Sport, Exercise and Health, University of Basel,

St Jakobsturm 320B, 4052 Basel, Switzerland

$\mathrm{Tel}+4$ I 6 I 2047483

Fax +4I 6I 2047489

Email markus.gerber@unibas.ch

\section{Dear editor}

In their letter, Hallgren, Vancampfort and Stubbs supported our claims ${ }^{1}$ that more systematic efforts are required to increase physical activity and cardiorespiratory fitness in psychiatric settings, and to better utilize the potential of exercise as a treatment in psychiatric care. They also shared our view that behavior skill training may be a promising avenue to increase exercise adherence. In this respect, Mota-Pereira et $\mathrm{al}^{2}$ showed that regular and moderately intensive walking improved symptoms of depression in treatment-resistant patients with major depressive disorders. Specifically, they employed both supervised and non-supervised techniques. The latter consisted of reminders to exercise by placing sports shoes by the front door, leaving a note on the main door or using cell phone reminders with a specific ringtone. Further, "social enhancers" were employed; patients were encouraged by and involved family members, in order to both remind them to be physically active and to exercise together with them. We hold that such pragmatic tricks are more efficient, compared to simply advising patients to increase their cardiorespiratory fitness levels. Further, we claim that "cardiorespiratory fitness" seems to be a rather academic, intellectual and "bulky" concept, which may be difficult to translate to patients in a comprehensible form (How does cardiorespiratory fitness feel, and what should I do to improve it?). Accordingly, we claim that the "next generation" of exercise interventions targeting patients with major depressive disorders should take into account which environmental, social and above all cognitive-emotional processes might boost and stabilize the social and cognitive determinants of exercise regulation. As a result of this, questions arise as to why it seems so difficult, even for people without psychiatric diagnoses, to maintain regular exercise regimes, resulting in the fact that physical inactivity is among the main causes of both somatic and psychiatric diseases worldwide..$^{3-5}$

We thank Hallgren, Vancampfort and Stubbs for their appreciatory comments and for sharing their own ideas. Hallgren et al complemented our perspectives with several important points, which we would like to comment on. In particular, they emphasized that the effectiveness of behavioral skill training has not yet been tested in patients with psychiatric disorders and that even small doses of physical activity can lead to lasting reductions in depressive symptoms among patients with mild-to-moderate depression. Here, again, we refer to the seminal work of Mota-Pereira et al. ${ }^{2}$ Moreover, Chalder et $\mathrm{al}^{6}$ recently showed, in a study with 361 participants who had consulted their general practitioner with symptoms of depression, that a protocol of three face-to-face sessions and 10 telephone calls with a trained physical activity facilitator (over an 8-month period) was associated with increased physical activity levels at the 4-month follow-up (adjusted odds ratio: 2.27, $P<0.01$ ). Nevertheless, given that behavior skill training might be a special challenge in psychiatric care due to unfavorable cognitive-emotional processes experienced by these patients (eg, hopelessness, pessimism, lack of motivation), we believe that more well-controlled intervention studies are needed to examine whether a generalization to psychiatric populations is possible or whether alternative approaches must be taken into consideration.

Hallgren et al's second claim (that even small doses of physical activity are able to decrease depressive symptoms) seems justified. Based on a study with 946 outpatients who were randomly assigned to an internet-based cognitive therapy, usual care by the physician or light, moderate or vigorous aerobic exercise, they concluded that after the end of the intervention phase, patients of all exercise groups reported lower levels of depressive symptoms compared to usual care, an effect which was maintained until 12 months after baseline assessment. ${ }^{7-9}$ In summary, these findings suggest that far less exercise is needed to decrease depressive symptoms than typically suggested in internationally accepted physical activity recommendations. ${ }^{10,11}$ Further, this pattern of results mirrors the findings of Mota-Pereira et al ${ }^{2}$ among treatment-resistant patients with major depressive disorders: while after 12 weeks, none of the 10 patients in the control condition showed any improvement (but also no aggravation), of the 19 patients in the walking group, $10(52.6 \%)$ remained in a state of depression, 4 patients (21\%) were responders and $5(26.3 \%)$ were fully remitted. Or simply put, in the walking group, improvements were 
observed in half of the patients with treatment-resistant major depression.

With regard to the question of how the "next generation" of research and interventions might look in this field of study, we would like to emphasize seven points:

First, we question the extent to which most physical activity recommendations are appropriate for patients with psychiatric disorders, as physical activity recommendations have generally been developed with a focus on the prevention of cardiovascular diseases. ${ }^{12,13}$ In this regard, in a recent study with patients suffering from stress-related exhaustion disorder,${ }^{14}$ we observed the following results: in originally inactive patients, compliance with physical activity recommendations 6 months after the end of multimodal treatment was associated with continued decreases in depression and burnout symptoms. Next, not surprisingly, continued physical inactivity was linked with a new rise in symptom severity. However, similar to Hallgren et a ${ }^{178}$ and Helgadóttir et al, ${ }^{9}$ we found that patients who only exercised 1-2 times per week (and thus, did not meet recommended physical activity standards) achieved comparable benefits to their counterparts with more frequent exercise involvement. ${ }^{14}$ In summary, these findings suggest that psychological symptoms can be prevented or improved with small amounts of exercise, below the levels recommended to improve cardiovascular health. ${ }^{15-17}$ Some of our studies even suggest that the way in which people think about their physical activity levels is more closely related to their psychological functioning than their self-reported exercise. ${ }^{18,19}$ However, since it is reasonable to assume that such minor doses of exercise are not sufficient to improve cardiorespiratory fitness, and thus have only a limited potential to enhance physical health and to reduce the premature mortality rate in people with psychiatric disorders, meeting current physical activity recommendations still seems to be a meaningful target for psychiatric patients.

Second, at a psychological level and from a self-efficacy perspective, we question the cognitive-emotional importance of the concept of "cardiorespiratory fitness" to motivate psychiatric patients to adopt more physically active lifestyles. We claim that this concept is too abstract, and that even for people without psychiatric issues, "cardiorespiratory fitness" is difficult to capture; accordingly, how should people aim for targets of which they have no (clear) mental representation? Poorly defined aims lack the capacity to improve goaloriented and behavior-steering cognitions. ${ }^{20-22}$ More specifically, we claim that any kind of physical activity and fitness target should be visualized so that patients with psychiatric issues can literally see their improvements. ${ }^{23}$ To this end, graphs, figures and appropriate technological tools are helpful, albeit not sufficient. We hold that encouragement through well-trained professionals is of key importance because patients with psychiatric disorders tend to bias and downplay improvements, or attribute any kind of improvement to external sources. ${ }^{24}$ Thus, instructors should emphasize that improvements with regard to physical activity and fitness are exclusively related to patients' efforts, hereby improving patients' self-efficacy. Moreover, we posit that doses of exercise should be increased gradually in order to avoid feelings of failure and helplessness, which might be counterproductive in the long run. ${ }^{25}$ Such an approach is also mirrored in the behavioral analysis as proposed by Kanfer and Saslow. ${ }^{26}$ Specifically, the authors highlight the importance of improving patients' self-observation and shifting self-evaluation from an unfavorable to a favorable evaluation.

Third, we strongly believe that the promotion of physically active lifestyles in people with psychiatric disorders needs professional stimulation and supervision, along with the training of practical behavioral techniques that facilitate exercise adherence, as impressively shown by Mota-Pereira et al in patients with treatment-resistant disorders, ${ }^{2}$ by Chalder et al in people diagnosed with an episode of depression ${ }^{6}$ and by many other researchers with other patient groups. ${ }^{27-35}$

Fourth, looking back, many previous studies have focused on short-term effects of exercise interventions, placing a particular focus on psychological symptoms, cardiorespiratory fitness and/or physiological mechanisms as outcome variables. Moreover, in an attempt to increase internal consistency and to draw conclusions about cause and effect, many of these studies have been carried out in strongly controlled settings. While these studies have laid important groundwork by raising our awareness that (a) in the short run, exercise activities and usual care or psychopharmacological treatment are similarly effective, and (b) exercise may be used as a valuable add-on to standard treatment, few efforts have been made to examine long-term effects. Nevertheless, many of these studies were atheoretical and have failed to integrate current knowledge from established behavior change models. As a consequence, few studies have tested whether the interventions had a positive impact on social, cognitive and affective factors involved in the regulation of physical activity and exercise behavior. ${ }^{36}$ Given this background, we reemphasize our claim that more systematic and theory-based efforts are needed to enable (and assess) long-term behavior change. ${ }^{37,38}$

Fifth, while we believe that motivational and volitional interventions are well suited to addressing explicit 
motivational processes such as self-efficacy beliefs, outcome expectancies, behavioral intentions, implementation intention or coping skills, sport and exercise scientists have recently highlighted the relevance of implicit attitudes in the regulation of exercise behavior. For instance, Conroy et $\mathrm{al}^{39}$ showed in a sample of healthy participants that implicit attitudes contributed to the prediction of physical activity beyond well-established predictors of intentional physical activity. Conroy et al therefore concluded that "physical activity motivation involves both explicit and implicit processes, and physical activity promotion efforts may be enhanced by attending to relevant implicit motivation processes" (p 112). Similar findings were reported by Bluemke et $\mathrm{al}^{40}$ and Chevance et al. ${ }^{41}$ Importantly, Antoniewicz and Brand ${ }^{42}$ have shown that among undergraduate students, implicit attitudes toward exercise can be improved through computer-based evaluative conditioning and that this procedure can move people toward developing an enjoyment of exercise. Given this background, future research could address the question of whether psychiatric patients and healthy controls differ with regard to their automatic evaluations of exercise. If this were the case, fostering simultaneously explicit and implicit motivational processes to promote increased lifestyle physical activity would seem a worthwhile endeavor in psychiatric care.

Sixth, Mothes et $\mathrm{al}^{43}$ showed that in healthy adult exercisers who believed that regular exercising was healthy, exercise had a stronger impact on both subjective and neurophysiological health outcomes than in participants who were less convinced of the health-enhancing potential of regular exercise. In patients with psychiatric disorders, it might be especially challenging to overcome negative automatic evaluations of exercise. We therefore emphasize that providers of physical activity and exercise programs should be aware that the affective responses during and after exercise will have a significant impact on whether participants will adhere to regular physical activity. ${ }^{44,45}$ Hence, in line with the work of Ekkekakis et al, ${ }^{46-48}$ we suggest that efforts are needed to make exercise for patients with psychiatric disorders as pleasant and enjoyable as possible, for example, by choosing the right activities and intensities or creating an autonomy-supportive climate. ${ }^{49,50}$

Seventh, we claim that more studies in naturalistic settings or based on patient registers are needed to find out whether the existing positive effects of exercise on psychological functioning (based on randomized controlled trials) can be replicated if physical activity and exercise programs are integrated in existing clinical structures. Finally, we claim that more information is required with regard to the costeffectiveness of exercise and physical activity (counseling) programs in psychiatric care in order to compare exercise therapy with more traditional treatments.

Again, we thank Hallgren et al for their important comments, and hope that our response will stimulate new and fruitful debates regarding the question of how "next generation" research and intervention programs may look in this field of research.

\section{Disclosure}

The authors report no conflicts of interest in this communication.

\section{References}

1. Gerber M, Holsboer-Trachsler E, Pühse U, Brand S. Exercise is medicine for patients with major depressive disorders: but only if the "pill" is taken! Neuropsychiatr Dis Treat. 2016;12:1977-1981.

2. Mota-Pereira J, Carvalho S, Silverio J, et al. Moderate physical exercise and quality of life in patients with treatment-resistant major depressive disorder. J Psychiatr Res. 2011;45(12):1657-1659.

3. Andersen LB, Mota J, Di Pietro L. Update on the global pandemic of physical inactivity. Lancet. 2016;388(10051):1255-1256.

4. Ding D, Lawson KD, Kolbe-Alexander TL, et al. The economic burden of physical inactivity: a global analysis of major non-communicable diseases. Lancet. 2016;388(10051):1311-1324.

5. Reis RS, Salvo D, Ogilvie D, et al; Lancet Physical Activity Series 2 Executive Committee. Scaling up physical activity interventions worldwide: stepping up to larger and smarter approaches to get people moving. Lancet. 2016;388(10051):1337-1348.

6. Chalder M, Wiles NJ, Campbell J, et al. Facilitated physical activity as a treatment for depressed adults: randomized controlled trial. BMJ. 2012;344:e2758.

7. Hallgren M, Kraepelien M, Öjehagen A, et al. Physical exercise and internet-based cognitive behavioural therapy in the treatment of depression: randomised controlled trial. Br J Psychiatry. 2015;207(3): 227-234.

8. Hallgren M, Helgadóttir B, Herring MB, et al. Exercise and internetbased cognitive behavioural therapy for depression: multicentre randomised controlled trial with 12-month follow-up. Br J Psychiatry. Epub 2016 Sep 8.

9. Helgadóttir B, Hallgren M, Ekblom Ö, Forsell Y. Training fast or slow? Exercise for depression: a randomized controlled trial. Prev Med. 2016; 91:123-131.

10. Haskell WL, Blair SN, Hill JO. Physical activity: health outcomes and importance for public health policy. Prev Med. 2009;49(4): 280-282.

11. Haskell WL, Lee IM, Pate RR, et al. Physical activity and public health. updated recommendation for adults from the American College of Sports Medicine and the American Heart Association. Med Sci Sports Exerc. 2007;39(8):1423-1434.

12. Paffenbarger RS Jr, Hyde RT, Wing AL, et al. The association of changes in physical activity level and other lifestyle characteristics with mortality among men. $N$ Engl J Med. 1993;328(8):538-545.

13. Paffenbarger RS Jr, Wing AL, Hyde RT. Physical activity as an index of heart attack risk in college alumni. Am J Epidemiol. 1978;108(3): 161-175.

14. Lindegård $\mathrm{A}$, Jonsdottir $\mathrm{IH}$, Börjesson $\mathrm{M}$, Lindwall M, Gerber M. Changes in mental health in compliers and non-compliers with physical activity recommendations in patients with stress-related exhaustion. BMC Psychiatry. 2015;15:272. 
15. Jonsdottir IH, Rödjer L, Hadzibajramovic E, Börjesson M, Ahlborg GJ Jr. A prospective study of leisure-time physical activity and mental health in Swedish health care workers and social insurance officers. Prev Med. 2010;51(5):373-377.

16. Lindwall M, Ljung T, Hadžibajramović E, Jonsdottir IH. Self-reported physical activity and aerobic fitness are differently related to mental health. Ment Health Phys Act. 2012;5(1):28-34.

17. Gerber M, Jonsdottir IH, Lindwall M, Ahlborg G Jr. Physical activity in employees with differing occupational stress and mental health profiles: a latent profile analysis. Psychol Sport Exerc. 2014;15(6):649-658.

18. Gerber M, Brand S, Holsboer-Trachsler E, Pühse U. Fitness and exercise as correlates of sleep complaints: is it all in our minds? Med Sci Sports Exerc. 2010;42(5):893-901.

19. Gerber M, Kellmann M, Elliot C, et al. Perceived fitness protects against stress-based mental health impairments among police officers who report good health. J Occup Health. 2014;55(5):376-384.

20. Locke EA, Latham GP. Building a practically useful theory of goal setting and task motivation. A 35-year odyssey. Am Psychol. 2002;57(9): $705-717$.

21. Sniehotta F. Towards a theory of intentional behaviour change: plans, planning and self-regulation. Br J Health Psychol. 2009;14(Pt 2): 261-273.

22. Sniehotta FF, Nagy G, Scholz U, Schwarzer R. The role of action control in implementing intentions during the first weeks of behaviour change. Br J Soc Psychol. 2006;45(Pt 1):87-106.

23. Gerber M, Oberer N, Pühse U. Beweg Dich gesund! Ein praktischer Ratgeber für ein körperlich aktives Leben [Move Healthy! A Practical Guide for a More Physically Active Lifestyle]. Aachen: Meyer \& Meyer; 2014. German.

24. Cristea IA, Huibers MJ, David D, et al. The effects of cognitive behavior therapy for adult depression on dysfunctional thinking: a meta-analysis. Clin Psychol Rev. 2015;42:62-71.

25. Gerber M, Jonsdottir IH, Arvidson E, Lindwall M, Lindegård A. Promoting graded exercise as a part of multimodal treatment in patients diagnosed with stress-related exhaustion. J Clin Nurs. 2015; 24(13-14):1904-1915.

26. Kanfer FH, Saslow G. Behavioral analysis: an alternative to diagnostic classification. Arch Gen Psychiatry. 1965;12:529-538.

27. Scholz U, Knoll N, Sniehotta FF, Schwarzer R. Physical activity and depressive symptoms in cardiac rehabilitation: long-term effects of a selfmanagement intervention. Soc Sci Med. 2006;62(12):3109-3120.

28. Gerber M, Fuchs R, Pühse U. Der Einfluss eines KurzInterventionsprogramms (MoVo-Lisa) auf das Bewegungsverhalten und die Determinanten körperlich-sportlicher Aktivität bei übergewichtigen und fettleibigen Personen [Effects of a short exercise counseling intervention on sport participation and cognitive-behavioral antecedents of sport participation in a sample of overweight and obese individuals]. Z Gesundheitspsychol. 2010;18:159-169. German.

29. Gerber M, Fuchs R, Pühse U. Follow-up of a short motivational and volitional exercise-intervention trial with overweight and obese individuals. Schweiz Z Med Traumatol. 2010;58(4):108-114.

30. Sniehotta FF, Scholz U, Schwarzer R. Action plans and coping plans for physical exercise: a longitudinal intervention study in cardiac rehabilitation. Br J Health Psychol. 2006;11(Pt 1):23-37.

31. Sniehotta FF, Scholz U, Schwarzer R, Fuhrmann B, Kiwus U, Voller H. Long-term effects of two psychological interventions on physical exercise and self-regulation following coronary rehabilitation. Int $J$ Behav Med. 2005;12(4):244-255.

32. Lippke S, Ziegelmann JP, Schwarzer R. Behavioral intentions and action plans promote physical exercise: a longitudinal study with orthopedic rehabilitation patients. J Sport Exerc Psychol. 2004;26(3):470-483.
33. Bolognesi M, Nigg CR, Massarini M, Lippke S. Reducing obesity indicators through brief physical activity counseling (PACE) in Italian primary care settings. Ann Behav Med. 2006;31(2):179-185.

34. Fuchs R, Goehner W, Seelig H. Long-term effects of a standardized group intervention on physical exercise and health: the MoVo-concept. J Phys Act Health. 2011;8(6):794-803.

35. Göhner W, Schlatterer M, Seelig H, et al. Two-year follow-up of an interdisciplinary cognitive-behavioral intervention program for obese adults. J Psychol. 2012;146(4):371-391.

36. Biddle SJ, Mutrie N. Psychology of Physical Activity: Determinants, Well-being and Interventions. London: Routledge; 2006.

37. Marcus BH, Forsyth LA. Motivating People to be Physically Active. Champaign: Human Kinetics; 2003.

38. Nigg CR. ACSM's Behavioral Aspects of Physical Activity and Exercise. Little Rock: Lippincott Williams \& Wilkins; 2013.

39. Conroy DE, Hyde AL, Doerksen SE, Ribeiro NF. Implicit attitudes and explicit motivation prospectively predict physical activity. Ann Behav Med. 2010;39(2):112-118.

40. Bluemke M, Brand R, Schweizer G, Kahlert D. Exercise might be good for me, but I don't feel good about it: do automatic associations predict exercise behavior? J Sport Exerc Psychol. 2010;32(2):137-153.

41. Chevance G, Caudroit J, Romain AJ, Boiché J. The adoption of physical activity and eating behaviors among persons with obesity and in the general population: the role of implicit attitudes within the Theory of Planned Behavior. Psychol Health Med. Epub 2016 Mar 7.

42. Antoniewicz F, Brand R. Learning to like exercising: evaluative conditioning changes automatic evaluations of 6 exercising and influences subsequent exercising behavior. J Sport Exerc Psychol. 2016;38(2): $138-148$.

43. Mothes H, Leukel C, Jo HG, et al. Expectations affect psychological and neurophysiological benefits even after a single bout of exercise. $J$ Behav Med. Epub 2016 Aug 9.

44. Rhodes RE, Fiala B, Conner M. A review and meta-analysis of affective judgments and physical activity in adult populations. Ann Behav Med. 2009;38(3):180-204.

45. Williams DM, Dunsiger S, Ciccolo JT, et al. Acute affective response to a moderate-intensity exercise stimulus predicts physical activity participation 6 and 12 months later. Psychol Sport Exerc. 2008;9(3): 231-245.

46. Ekkekakis P. Let them roam free? Physiological and psychological evidence for the potential of self-selected exercise intensity in public health. Sports Med. 2009;39(10):857-888.

47. Ekkekakis P, Parfitt G, Petruzzello SJ. The pleasure and displeasure people feel when they exercise at different intensities: decennial update and progress towards a tripartite rationale for exercise intensity prescription. Sports Med. 2011;41(8):641-671.

48. Ekkekakis P, Hall EE, Petruzzello SJ. The relationship between exercise intensity and affective responses demystified: to crack the 40-year-old nut, replace the 40-year-old nutcracker! Ann Behav Med. 2008;35(2):136-149.

49. Williams DM. Exercise, affect, and adherence: an integrated model and a case for self-paced exercise. J Sport Exerc Psychol. 2008;30(5): 471-496.

50. Schneider ML, Kwan BM. Psychological need satisfaction, intrinsic motivation and affective response to exercise in adolescents. Psychol Sport Exerc. 2013;14(5):776-785. 
Dove Medical Press encourages responsible, free and frank academic debate. The content of the Neuropsychiatric Disease and Treatment 'letters to the editor' section does not necessarily represent the views of Dove Medical Press, its officers, agents, employees, related entities or the Neuropsychiatric Disease and Treatment editors. While all reasonable steps have been taken to confirm the content of each letter, Dove Medical Press accepts no liability in respect of the content of any letter, nor is it responsible for the content and accuracy of any letter to the editor.

Neuropsychiatric Disease and Treatment

Dovepress

\section{Publish your work in this journal}

Neuropsychiatric Disease and Treatment is an international, peerreviewed journal of clinical therapeutics and pharmacology focusing on concise rapid reporting of clinical or pre-clinical studies on a range of neuropsychiatric and neurological disorders. This journa is indexed on PubMed Central, the 'PsycINFO' database and CAS, and is the official journal of The International Neuropsychiatric Association (INA). The manuscript management system is completely online and includes a very quick and fair peer-review system, which is all easy to use. Visit http://www.dovepress.com/testimonials.php to read real quotes from published authors.

Submit your manuscript here: http://www.dovepress.com/neuropsychiatric-disease-and-treatment-journal 